\title{
O Desenvolvimento do Bebê e sua Complexa Relação com Determinantes Sociais da Saúde
}

\author{
Cristina Saling Kruel - Universidade Franciscana, Santa Maria, Brasil \\ Ana Paula Ramos de Souza - Universidade Federal de Santa Maria, Santa Maria, Brasil
}

\begin{abstract}
Resumo
Neste artigo, objetivou-se averiguar a relevância dos Determinantes Sociais da Saúde para o desenvolvimento do bebê com enfoque no desenvolvimento da linguagem. Além disso, realizou-se uma reflexão sobre as contribuições do estudo de casos como forma de adotar uma postura compreensiva e dinâmica na análise do desenvolvimento do bebê. Tais aspectos foram analisados com destaque para a relação de mutualidade mãe-bebê. Para tanto, foram acompanhadas duas díades mãe-bebê filmadas em três etapas da vida dos bebês: entre 20 e 30 dias; entre 80 e 90 dias; e entre 110 e 120 dias. As filmagens foram transcritas e analisadas partindo de fragmentos que ilustram a evolução longitudinal dos casos. Demonstrou-se que esse método de pesquisa permite compreender que os Determinantes Sociais da Saúde incidem de maneira acentuada sobre o desenvolvimento do bebê. Destaca-se que o enfoque na relação mãe-bebê de mutualidade amplia o escopo da atenção materno-infantil e permite verificar a sustentação do cuidado ao bebê por meio da articulação corpo/linguagem.

Palavras-chave: fatores socioeconômicos, maternidade, desenvolvimento do bebê
\end{abstract}

The Baby Development and its Complex Relations with the Social Determinants of Health

\begin{abstract}
This article aims at verifying the relevance of the Social Determinants of Health for infant development focusing on language development. We analyzed the case study contributions as a way to adopt an understanding and dynamic posture in the analysis of infant's development. These aspects were analyzed with emphasis on the mutual mother-infant relationship. For this purpose, we observed two mother-infant pairs filmed in three stages of the babies' life: between 20 and 30 days, between 80 and 90 days, and between 110 and 120 days. The footage was transcribed and analyzed starting from fragments illustrating the longitudinal course of the cases, demonstrating that this method of research allows the understanding of how Health Social Determinants focus on the development of the baby. It stands out that the observation of the mother-infant relationship increases the scope of maternal-infant care and allows checking the support of infant care through the body/ language articulation.

Key Words: Socioeconomic Factors; Motherhood; Baby Development.
\end{abstract}

El Desarrollo del Bebé y su Compleja Relación con Determinantes Sociales de la Salud

\section{Resumen}

El objetivo de este artículo consiste en averiguar la pertinencia de los Determinantes Sociales de la Salud para el desarrollo del bebé,con enfoque en el desarrollo del lenguaje. También se realizó una reflexión sobre las contribuciones del estudio de casos, como forma de adoptar una postura comprensiva y dinámica en el análisis del desarrollo del bebé, destacándose la relación mutualidad madre-bebé. Se observaron dos duplas de madre-bebé filmados en tres etapas diferentes de sus vidas: entre 20 y 30 días, entre 80 y 90 días y entre 110 y 120 días. Se transcribieron y analizaron las filmaciones a partir de fragmentos que ilustraban la evolución longitudinal de los casos, demostrando que este método de investigación permite comprender de qué forma los Determinantes Sociales de la Salud, inciden de manera acentuada en el desarrollo del bebé. Se destaca que el foco en la relación de mutualidad madre-bebé amplía el objetivo de atención materno-infantil y permite comprobar el aumento de cuidado con el bebé por medio del lenguaje de articulación cuerpo/lenguaje.

Palabras-clave: Factores socio económicos; Maternidad; Desarrollo del bebé.

\section{Introdução}

Tradicionalmente, é possível identificar ao menos dois grandes enfoques no estudo do desenvolvimento infantil: o enfoque educacional, cuja base teórica historicamente esteve mais ligada às ciências humanas, e o clínico, cuja influência maior provém das ciências da saúde (Rodrigues, 2012; Taques \& Rodrigues, 2006). Os estudos abordam o desenvolvimento, predominantemente, por meio de testes e escalas, sobretudo em relação a efeitos de fatores biológicos, como a prematuridade (Barre, Morgan, Doyle, \& Anderson, 2011; Fernandes et al., 2012)<32 weeks' gestational age. Ambos os enfoques podem ser observados no campo da psicologia e há os que questionam a avaliação dos comportamentos e habilidades da criança sem que haja observação do contexto e das relações dela com o ambiente (Wanderley, Weise, \& Brant, 2008).

O estudo do desenvolvimento do bebê implica na consideração do seu potencial para o desenvolvimento, aspectos orgânicos e fisiológicos e também das suas relações inicias e nas interações de cuidado. Quanto ao 
cuidado, é necessário considerar a saúde e o bem-estar do cuidador principal, bem como a sua capacidade de estabelecer relações íntimas e afetivas com o bebê. Assim, a avaliação da relação de mutualidade mãe-bebê pode ser um indicador importante para a compreensão de como se dá o cuidado materno. Winnicott define essa relação como o começo de uma comunicação entre a mãe e seu bebê, que é sutil nas primeiras semanas de vida dele e pode ser de difícil apreensão por um observador que contempla a interação mãe-bebê, ainda que alguns bebês se demonstrem particularmente fisgados pelo olhar materno desde cedo. A mutualidade indica uma relação de reciprocidade e sincronia entre a dupla, que se constrói muito cedo, já nas unidades obstetrícias (Winnicott, 1969).

A sustentação do cuidado ao bebê ocorre por meio da articulação corpo/linguagem, o que alimentará o processo de amadurecimento dele e sua constituição linguística. Esta se dará pela construção de uma posição discursiva, sustentada na relação entre sistema semiótico verbal materno e sistema semiótico corporal do bebê (Kruel, 2015; Kruel, Rechia, Oliveira, \& Souza, 2016; Ramos \& Flores, 2013). Destaca-se, nesse processo fundamental para o desenvolvimento satisfatório do bebê, o contexto em que a mãe e o bebê vivem, as condições sociais que determinam a sensação de amparo e segurança à mãe, as condições de saúde orgânica da mãe e do bebê. Esse cuidado se realiza pela atenção e sintonia da mãe às demandas do bebê, que reside sobre um estado de sensibilidade aumentada e ao qual Winnicott chamou de preocupação materna primária (Winnicott, 2006). Essa sensibilidade só poderá manifestar-se se forem garantidas as condições sociais e de saúde para a mãe e, gradualmente, irá se arrefecendo à medida que o bebê desenvolve mais recursos comunicativos. É importante observar que a mutualidade mãe-bebê está influenciada por características individuais da mãe, por suas condições sociais e por características do bebê, todas mutáveis no decorrer do desenvolvimento dos primeiros meses (Kruel, 2015), o que põe em questão a maneira casuística, estanque e diretiva como os estudos têm exposto a influência dos Determinantes Sociais para o desenvolvimento do bebê e alerta para a complexidade dos efeitos sociais sobre o desenvolvimento infantil, como se verá no relato de casos.

A Comissão de Determinantes Sociais da Organização Mundial de Saúde (OMS), criada em 2005 (CDSS-Comissão para os Determinantes Sociais da Saúde, 2010, p.1), define os Determinantes Sociais da
Saúde considerando que "determinantes estruturais e as condições de vida quotidianas constituem os Determinantes Sociais da Saúde e são responsáveis pela maior parte das desigualdades na saúde dentro e entre países". Portanto, eles estão relacionados às condições em que uma pessoa vive, incluindo fatores de trabalho, sociais, econômicos, culturais, étnicos/raciais, psicológicos e comportamentais que influenciam a ocorrência de problemas de saúde e na identificação de fatores de risco à população (Fundação Oswaldo Cruz (FIOCRUZ), 2015).

Entre os Determinantes Sociais da Saúde analisados nos estudos quantitativos com enfoque em bebês e crianças estão a idade e a escolaridade maternas, a renda familiar, o número de irmãos, a mãe ter ou não apoio do cônjuge. Já entre os fatores biológicos, a prematuridade do bebê é destacada, na maior parte dos estudos, em sua relação com o desenvolvimento infantil (Amorim et al., 2009; Andrade, Santos, Bastos, Pedromônico, Almeida-Filho, \& Barreto, 2005; Fraga, Linhares, Carvalho, \& Martinez, 2008; Sabroza, Leal, Gama, \& Costa, 2004; Voss, W., Jungmann, T. Wachtendorf, \& Neubauer, 2012). Outros estudos, com interface no campo psicanalítico, sobretudo aqueles que trabalham com a noção de risco psíquico, que procuram estabelecer um paradigma indiciário e menos determinista na relação entre desenvolvimento e risco, também utilizaram Determinantes Sociais para observar a relação entre aspectos psicossociais e desenvolvimento infantil (Beltrami, Moraes, \& Souza, 2013; Crestani, Mattana, Moraes, \& Souza, 2013; Pretto-Carlesso, Souza, \& Moraes, 2014).

A idade e a escolaridade maternas estão entre os Determinantes Sociais maternos mais estudados em sua relação com o desenvolvimento infantil. Já como condições do ambiente no suporte à maternidade estão as condições psicossociais, como a existência ou não de apoio do cônjuge e de redes sociais, a presença de crise situacional e, entre os aspectos clínicos da mãe, encontram-se a presença de psicopatologias e o estado de humor materno, entre outras (Beltrami et al., 2013; Pretto-Carlesso et al., 2014).

Diversos artigos apontam a gravidez na adolescência como uma situação de risco, considerando tanto as condições psicossociais da mãe quanto os limites impostos por fatores biológicos. Santos e Schor (2003) analisaram as diferentes formas de vivenciar a maternidade na adolescência precoce a partir da subjetividade da própria adolescência, demonstrando que existem adolescentes que a vivenciam de forma positiva e outras de forma negativa, sobretudo aquelas que tiveram sua 
trajetória de estudo e trabalho interrompida por insuficiência de instrumentos de apoio no cuidado à criança (Ogido \& Schor, 2012; Santos \& Schor, 2003). Já Pariz, Mengarda e Frizzo realizaram uma revisão sistemática entre 1998 e 2008 e observaram que há uma dificuldade de comunicação entre a esfera familiar, política e social no cuidado às adolescentes, que têm como consequência a falta de clareza necessária para fazer escolhas mais conscientes e assertivas, inclusive sobre a maternidade (Pariz, Mengarda, \& Frizzo, 2012).

Em relação a aspectos biológicos, Vieira, Bicalho, Silva e Barros Filho (2007) abordaram o desenvolvimento e o crescimento de filhos de mães adolescentes em comparação aos filhos de mães adultas, por meio da avaliação de variáveis maternas médicas e sociais, como dados do parto, medidas antropométricas das crianças, necessidade de hospitalização no primeiro ano de vida, utilização de creches e o desenvolvimento neuropsicomotor das crianças. Os autores observaram que, com um ano de idade, os filhos das adolescentes apresentaram peso e índice de massa corpórea menor do que os filhos de mães adultas, não havendo distinções quanto ao desenvolvimento neuropsicomotor (Vieira, Bicalho, Silva, \& Barros Filho, 2007).

Ainda no campo de discussão sobre a maternidade, distinguindo sua ocorrência na adolescência da fase adulta, Novellino (2011) analisou os dados de mães adolescentes a partir de uma leitura sociodemográfica dos rendimentos mensais dos domicílios em que vivem, por meio de análise quantitativa dos dados secundários da Pesquisa Nacional por Amostra de Domicílios (PNAD) entre os anos de 2001 a 2008. Entre as conclusões, observou-se maior número de mães adolescentes em famílias com até dois salários mínimos, sobretudo, com até um salário mínimo (6\% a mais), e uma diminuição de até cinco pontos nos grupos com renda entre cinco e 10 salários mínimos. Outro resultado importante é que apenas $30 \%$ de mães adolescentes frequentavam a escola, contra $90 \%$ de adolescentes sem filhos. Em relação à ocupação, mais de $60 \%$ das adolescentes, com ou sem filhos, não eram ativamente econômicas (Novellino, 2011). Essa situação é agravada pelos problemas de gênero ainda presentes, apesar das políticas nacionais instauradas a partir da década de 90 terem diminuído a mortalidade neonatal (Santos Neto, Alves, Zorzal, \& Lima, 2008). Mulheres em situação de vulnerabilidade social, com baixa escolaridade, trabalho precário informal apresentam obstáculos para realização de projetos de vida, mesmo diante de políticas afirmativas como o Bolsa
Família, pois carecem da articulação com ações estruturais (Magalhães et al., 2011).

Além do efeito da baixa renda em si, Ferreira e Latorre (2012) observaram que a alta prevalência de doenças mentais se relaciona à desigualdade na renda $\mathrm{e}$ ao baixo capital social no adulto, que se dá por efeitos psicossociais, como humilhação e perda de autoestima (Ferreira \& Latorre, 2012), também observado em outro estudo que expõe a limitação do modelo biomédico e as alterações nos papéis femininos no século passado como aspectos que dificultam a transformação das políticas de saúde (Pegoraro \& Caldana, 2008) e que abordem o potencial promocional e preventivo na atenção básica (Moliner \& Lopes, 2013; Pereira \& Costa-Rosa, 2012; Moliner \& Lopes, 2013).

Portanto, neste artigo, objetivou-se averiguar a relevância dos Determinantes Sociais da Saúde para o estudo do desenvolvimento do bebê, com enfoque no desenvolvimento da linguagem. Entende-se que o desenvolvimento da linguagem pode ser um aspecto revelador do processo de amadurecimento do bebê, pois não raro as crianças em risco psíquico demonstram dificuldades relacionadas à organização do pensamento e à comunicação (Kruel, 2015). Além disso, realizou-se uma reflexão sobre as contribuições do estudo de casos longitudinais como forma de adotar uma postura compreensiva e dinâmica na análise do desenvolvimento do bebê, considerando-se a relação dialética entre aspectos biológicos, psicossociais e comportamentais. Ambos os objetivos estão relacionados e tem como pano de fundo a ideia de que o cuidado ao bebê ocorre por meio da articulação corpo/linguagem, dependendo das condições de vida dos cuidadores, que são mutáveis ao longo do tempo. Portanto, as análises foram realizadas com destaque para a relação mãe-bebê de mutualidade.

\section{Método}

\section{Participantes}

Neste artigo, são apresentados dados de duas díades mãe-bebê acompanhadas e filmadas em sua interação logo após o nascimento dos bebês até os quatro meses de idade. Trata-se de uma amostra de conveniência selecionada em uma maternidade pública, a partir dos Determinantes Sociais da Saúde comuns a ambas as díades, como nível de renda familiar similar, e determinantes diversos, como idade, experiência de vida, apoio social, tempo de relação afetiva/amorosa com o pai do bebê, idade e escolaridade das mães, que permitem uma discussão dos seus efeitos na relação com os filhos. M1 
tinha 16 anos, B1 era o seu primeiro filho, fruto de uma relação afetiva/amorosa instável de um ano de duração. M2 tinha 23 anos, B2 era sua segunda filha, fruto de uma relação estável de seis anos.

\section{Instrumentos}

Como instrumentos de pesquisa, compreende-se a entrevista semiestruturada para coleta de dados sociodemográficos e as transcrições ortográficas das filmagens das interações familiares. As filmagens foram antecedidas de um rapport, ou seja, uma conversa informal com a família com a pretensão de familiarizar a todos com a câmera e com a presença da pesquisadora. A conversa incluía perguntas sobre o desenvolvimento do bebê, o cotidiano da família e quaisquer outros assuntos mencionados pelos familiares. Cada filmagem durou, em média, 20 minutos.

\section{Procedimentos}

A pesquisa foi aprovada pelo comitê de ética em pesquisa da instituição sob o número CAEE1154311.2.1.0000.5346, e os voluntários que concordaram em participar assinaram o Termo de Consentimento Livre e Esclarecido. A coleta abrangeu três etapas, tendo ocorrido a primeira entre 20 e 30 dias de vida dos bebês, a segunda entre 80 e 90 dias, e a terceira, entre 110 e 120 dias, quando eles completaram quatro meses de idade. Trata-se, portanto, de um estudo de casos longitudinal (Yin, 2001). As coletas foram domiciliares em dia agendado com a família, e as filmagens incluíram cenas da rotina familiar, concentrando-se, nas primeiras duas etapas da coleta, na cena de amamentação, captando um momento do cotidiano familiar.

Para a análise, foi realizada a transcrição ortográfica de cenas, com linhas dos interlocutores, que descrevem as relações mãe-bebê, e destes com o pesquisador e demais familiares, com o intuito de verificar como os processos interpretativos maternos estavam ancorados na relação de mutualidade mãe-bebê. Para efetivar essa análise, as filmagens foram transcritas, considerando que a transcrição linguística decorre tanto da instância enunciativa em que o dado é produzido (no momento da entrevista e da filmagem) quanto do momento da transcrição, que também é produto de enunciação (Deus, 2010). Para este artigo, foram analisadas as informações principais de cada caso e trazidos exemplos da transcrição que vão construindo a evolução de cada díade, tendo em vista os efeitos de aspectos sociais sobre essa relação e seus efeitos complexos no desenvolvimento infantil.

\section{Resultados e Discussão}

Nessa seção, inicialmente, os casos serão apresentados e discutidos separadamente para que as especificidades de cada um sejam discutidas em uma análise compreensiva sobre a influência de aspectos biológicos, psicossociais e comportamentais, no desenvolvimento do bebê, com destaque para a relação mãe-bebê de mutualidade e o desenvolvimento de linguagem do bebê. Posteriormente, será exposta uma síntese dos casos, com ênfase nos Determinantes Sociais da Saúde, buscando traçar um paralelo entre as experiências relatadas.

\section{Caso 1}

M1 é uma jovem de 16 anos, e B1 é seu primeiro filho. Segundo M1, o bebê foi conscientemente planejado por ela e o pai da criança P1, de 15 anos. Ainda no hospital, horas depois do nascimento de B1, M1 estava sorridente e parecia encantada com o seu bebê. Estava acompanhada de sua irmã, de 20 anos, que também tinha uma filha de dois anos. M1 contou que iria morar com o pai da criança, provisoriamente, na casa da tia dele, pois não conhecia seu pai, e sua mãe havia falecido há menos de um ano por complicações respiratórias consequentes da contaminação pelo vírus da imunodeficiência humana (HIV). Em termos socioeconômicos, a família apresentava evidente dificuldade financeira, com local de moradia incerto e renda familiar de um salário mínimo mensal, em média. M1 não exercia uma atividade profissional remunerada às vésperas do nascimento de B1, portanto, não usufruía de licença-maternidade remunerada, pois fora doméstica apenas até os primeiros meses de gravidez e sem registro na carteira profissional. P1 trabalhava como auxiliar de pedreiro de maneira informal e a sua remuneração era inconstante.

No primeiro encontro, no hospital, M1 contou que desejava amamentar o seu filho e admirava a sua irmã que ainda amamentava a sobrinha. As duas sorriram e contaram que a menina de dois anos mamava de qualquer jeito, sentada, deitada e, até mesmo, em pé, quando a mãe estava sentada em uma cadeira.

$\mathrm{Na}$ ocasião da primeira coleta na residência, B1 completava 21 dias de vida e M1 estava magra, não havia resquícios da barriga da gravidez. M1 conduziu a pesquisadora até a sua casa, um pequeno cômodo de madeira e papelão, localizado em um terreno no qual estavam dispostas mais cinco pequenas casas, incluindo a da mãe e da tia de P1, que eram maiores e equipadas 
com banheiro e cozinha, já as demais eram compostas por cômodos de três ou quatro metros quadrados, aparentemente sem encanamentos, onde cabia uma cama, um sofá e uma pequena cômoda, como a casa de M1.

M1 sentou-se sobre a cama que ocupava quase todo o cômodo e relatou a respeito das dificuldades que enfrentava para amamentar. Contou que sentia muita dor, mas que preferia chorar amamentando, a deixar seu bebê chorando de fome. Era um dia frio do mês de junho e ela estava com uma calça fina e chinelos de dedo, já B1 estava bem agasalhado, envolto por um cobertor e dormia. Ela também relatou que P1 estava trabalhando como auxiliar de pedreiro e voltaria para casa mais tarde.

Apesar dos recursos financeiros escassos e da precária moradia, B1 aparentava estar bem cuidado, agasalhado e limpo, imagem que contrastava com a de M1, que parecia cansada e pouco nutrida. Notava-se um grande investimento, em termos de cuidado, em B1, e M1 demonstrava-se dedicada ao bebê, o que sugere que ela estava vivenciando o estado de preocupação materna primária, proposto por Winnicott (2006). Apesar das más condições de vida de M1, ela parece exceder à regra ao proposto pelo próprio psicanalista que sugeriu que esse estado de sensibilidade aumentada se instauraria na mulher pouco antes de o bebê nascer, se ela estivesse adequadamente assistida por seu companheiro e desfrutando de boas condições afetivas, de suporte social e econômicos. M1 conseguia estabelecer as demandas de seu bebê e atendê-las de modo apropriado e com segurança.

Quando M1 mencionou que preferia amamentar chorando a deixar o seu filho chorando de fome, a preocupação materna primária (Winnicott, 2006) evidenciou-se também em seu discurso, pela intensa identificação de M1 com o seu bebê e a percepção de que ela tem mais condições de suportar o desconforto físico do que ele. M1 parecia reconhecer a fragilidade de seu bebê em contraponto à condição amadurecida dela.

M1 disse que ambos, pai e mãe, estavam muito felizes com a chegada de B1 e que o bebê acordava somente para mamar, enquanto B1 estava no colo de M1 e dormia. Quando M1 notou a expressão de desconforto dele, logo retirou a chupeta lentamente da boca do bebê e ofereceu o seio dizendo: "Dá esse bico pa mim, dá esse biiico".

Durante toda a cena, enquanto mamava, B1 permanecia de olhos fechados e manifestava o seu desconforto por meio de vocalizações, expressões faciais e movimentos dos seus braços e mãos. M1 fez a leitura do desconforto expresso por seu bebê como fome e ofereceu o seio, apesar da dor que sentia. B1 estava por completar um mês de vida, portanto, pode-se supor que ele desfrutava de uma consciência incipiente da continuidade do ser, incapaz de perceber a realidade como externa a ele (Winnicott, 2006). Desse modo, manifestava o seu desconforto permanecendo de olhos fechados e abria a boca com a segurança de que algo surgiria para atender a sua necessidade, tendo em vista a rotina de amamentação que já se estabelecera.

$\mathrm{Na}$ segunda etapa da coleta, B1 estava com 80 dias de vida. M1 estava em frente à sua casa sentada sob o sol, na companhia de uma criança de quatro anos (sobrinha de seu companheiro) e uma senhora (tia de seu companheiro). M1 parecia ainda mais magra. Enquanto M1 amamentava B1, chegou também sua irmã mais velha, de 20 anos. A análise das cenas demonstrou que a mutualidade mãe-bebê se mantinha e a mãe conseguia manter um cuidado satisfatório ao seu bebê, o que vai se modificando na terceira etapa, quando B1 estava com 111 dias de vida.

Nessa etapa da coleta, M1 estava novamente com B1 no pátio das casas que dividem o terreno e aparentava estar incomodada com a intensa agitação do ambiente e confidenciou à pesquisadora que estava enfrentando dificuldades no seu relacionamento com P1, porque, na percepção dela, ele mantinha hábitos que não eram mais compatíveis com as necessidades de descanso e cuidado de B1, como jogar videogame com os amigos ou ouvir música em volume alto quando B1 estava dormindo. M1 comentou também sobre a sua dificuldade em ser ouvida e respeitada por P1, desgosto que se somava a dificuldades financeiras enfrentadas pelo casal. Ao ser questionada pela pesquisadora sobre a rede de apoio e sobre seus planos para melhorar sua condição, M1 contou que planejava ir morar com uma tia, na região metropolitana do estado. Percebia-se, portanto, um maior desamparo e cansaço em M1 do que nas duas coletas anteriores, o que era visível em sua aparência física fragilizada e em seu relato.

Aparentemente, B1 defendia-se do sofrimento materno, pois não correspondia às investidas de M1 para que ele sorrisse e desviava o olhar, quando ela olhava em sua direção, o tocava com os dedos das mãos e repete: "Psiu, psiu. Dá uma risada pa mim, dá uma risada pa mim. Cadê a risada, cadê os denti? Tu não vai dá risada pa mãe? Hein? Dá risada pa mim, dá risada pa mim". Nessa cena, percebe-se que, por não poder apreciar a vivacidade materna, o bebê produz uma defesa, pois suas possibilidades de percepção do ambiente 
estão se ampliando (Winnicott, 2012). M1 demonstra ser uma mãe amorosa e, não obstante, tem como sua principal realização o cuidado ao seu bebê, porém, nessa etapa da coleta, ela se esforça para manter-se sorrindo e estimular B1 a sorrir. Evidentemente, pelo sofrimento verbalizado e expresso por M1, o sorriso e as brincadeiras endereçadas a B1 não são espontâneos e B1 não corresponde a sua convocação, fato que corrobora a proposição de que os bebês demonstram uma apetência muito maior para o verdadeiro manhês do que para o falso (Laznik, 2013).

Chama a atenção o intenso desamparo vivenciado por M1, que aparenta ter pouco apoio social e emocional. Ela se refere, em especial, à ausência de sua mãe: "De quem eu mais sinto falta, às vezes, é da minha mãe. Por causa que, quando eu namorava com ele, eu vinha aqui posar. Às vezes, ele brigava comigo, eu ia embora, né? Pra casa da minha mãe. Agora quando a gente briga não tem pra onde eu ir". A esse respeito, estudos nacionais atuais que apontam que, quando uma mulher jovem se torna mãe, a presença do referencial materno de sua própria mãe torna-se muito importante (Pedrosa, 2012). No caso de M1, a ausência de sua mãe soma-se às dificuldades financeiras, conjugais e de rede de apoio e, aos poucos, reflete-se nas cenas de interação com o bebê. Percebe-se que a crescente capacidade do bebê em perceber sua mãe o faz defender-se de sua tristeza, o que tem efeitos na interação e pode colocar em risco seu desenvolvimento, pois o bebê e a mãe começam a parar de desenvolver uma linguagem particular entre si (Laznik, 2013). Esse fato se reflete na ausência de vocalizações de B1 nessa etapa, o que é um indicativo de que o desenvolvimento de linguagem pode estar em risco.

\section{Caso 2}

M2 tem 23 anos, e B2 é sua segunda filha da união com P2, de 24 anos. A primogênita do casal tem quatro anos de idade. $\mathrm{Na}$ primeira etapa da coleta domiciliar de dados, M2 esperava em frente à pequena casa de madeira com um largo sorriso e logo disse: "Eu te falei que era a última casa antes do morro. Que bom que tu achou. Quer um doce de moranga?". Havia um grande varal em frente a casa, repleto de pequenas peças de roupa cor-de-rosa e lilás. A casa era simples, de um único cômodo, com um armário que fazia limite entre a sala, a cozinha e o dormitório. Mas era bem equipada e aparentemente nada faltava à família. A renda familiar informada era de um salário mínimo e meio, fruto da atividade profissional realizada por P2. M2 não realizava trabalho remunerado.
B2 estava dormindo no carrinho, bem agasalhada com uma roupa de tricô e luvas de lã. A primogênita estava em casa por ter sido liberada mais cedo da escola e brincava com uma menina de dois anos. M2 teve a primeira filha aos 19 anos de idade, tendo planejado a gravidez, assim como a concepção da segunda filha.

Ela dedicava-se exclusivamente ao lar e ao cuidado às filhas e contou que conseguiu concluir o Ensino Médio depois do nascimento da primogênita, estudando à noite, quando o seu companheiro permanecia em casa cuidando da menina. Além disso, contou que tem achado B2 mais ativa e responsiva que sua primeira filha quando tinha a mesma idade. Mencionou o quanto a bebê era esperta, olhava para tudo atentamente e também era tranquila e dormia bem à noite: "Ela não dá trabalho nenhum".

Durante as coletas de dados, M2 se demonstrava disponível afetivamente para o cuidado às filhas e conseguia conciliá-lo às demandas das duas meninas, ainda que demonstrasse ter dúvidas quanto ao manejo e sinais de cansaço habituais. M2 era falante e sorria com frequência, evidenciando vivacidade e entusiasmo, aspectos da sua personalidade que, certamente, seriam apreciados por $\mathrm{B} 2$ ao longo do seu processo de amadurecimento. $\mathrm{O}$ ambiente dinâmico e atento proporcionado à bebê parecia favorecer a integração psicossomática de $\mathrm{B} 2$, conforme pode ser visto na cena em que M2 se dirige ao carrinho para pegar a bebê que chorava e movimentava os braços, enquanto falava em manhês: "Aai, minha beiçuda, o que que é? Por que esse beiço meu deux? Qué um mamazinho, qué? " No que se refere à linguagem, observa-se que M2 fala com B2 por meio de uma fala melódica e afetuosa, o manhês que fisga o bebê para a interação, como ocorre com B2.

$\mathrm{Na}$ segunda etapa da coleta domiciliar, M2 estava com B2, com oitenta e sete dias de idade e sua filha primogênita. M2 parecia disposta e logo se dirigiu à bebê, tirando-a do carrinho. Em poucos minutos, B2 adormeceu e foi colocada novamente no carrinho, ficando ao lado da mãe, que relatava a rotina à pesquisadora. B2 acordou e começou a vocalizar, olhando em direção à mãe. Esta relatou que B2 era uma bebê insaciável, o que se percebia em sua forma física e também por sua vivacidade e interesse no ambiente, maiores do que a irmã mais velha, o que anuncia a previsão de Winnicott (2012) ao afirmar que o bebê não deve ser pensado como um indivíduo moldado pelo ambiente, pois contribui em seu processo de amadurecimento e direciona também o tipo de cuidado que recebe. As diferenças entre B2 e sua irmã não eram motivo 
de desagrado da mãe, que desfrutava do processo de amadurecimento da sua filha, de modo a reconhecer o que lhe era peculiar e reagir às suas necessidades à medida que essas se apresentam.

$\mathrm{Na}$ terceira etapa da coleta, B2 completava 110 dias e estavam em casa M2, com B2 e a filha de quatro anos. M2 estava sentada no sofá, com B2 em seu colo na posição em pé. A irmã de quatro anos estava diante das duas brincando com um telefone celular e tirando fotografias.

Observava-se que o aspecto geral de B2 era de uma criança bem cuidada e sustentada por sua mãe em seu processo de amadurecimento. Possivelmente, o pai de B2 participe ativamente do cuidado, pois ele sempre é lembrado por M2 durante as coletas, por meio de histórias ou fotos de família que ela mostrava com contentamento para a pesquisadora. Além disso, aparentemente a família desfrutava de momentos prazerosos, como passeios pelo centro da cidade, visita ao shopping e sorvete aos finais de semana. M2 relatava esses momentos com satisfação e diz que "não precisa ter muito dinheiro para passear".

$\mathrm{Na}$ terceira etapa da coleta de dados, em que B2 estava prestes a completar quatro meses de vida, observava-se que ela era competente ao manifestar a sua demanda por meio de seu comportamento, pois abria a boca, girava o corpo em direção ao seio, ou buscava outro objeto que lhe interessasse, utilizando diferentes recursos de linguagem. M2 convocava B2 a assumir um lugar discursivo quando questionava "O que? Quer mamá, né?”, ao qual a bebê correspondia prontamente, emitindo sons curtos, longos e diferentes.

Toda a manifestação corporal e sonora de B2 era interpretada por sua mãe, que definia, quando o caso, que a bebê estava com fome. Conforme já mencionado, a interpretância pode ser compreendida como princípio fundamental para se pensar a relação semiótica corporal do bebê, como a viabilidade de sua inserção na ordem simbólica da linguagem, quando a mãe coloca em palavras a sua interpretação. Nessa cena, percebia-se uma relação de homologia entre a semiótica corporal do bebê e o sistema linguístico materno, que permitiria a B2 acessar o signo linguístico, favorecendo a aquisição da linguagem. Portanto, a mutualidade entre M2 e B2 se expressava tanto no cuidado físico quanto na sustentação linguística.

Considerando os casos apresentados, parece ser importante partir daquilo que é comum entre as duas famílias acompanhadas, para se traçar um paralelo entre as experiências relatadas. Trata-se de famílias constituídas por pais jovens, o primeiro casal parental (M1e P1) era adolescente, a mãe tinha 16 e o pai tinha 15 anos, e o segundo casal (M2 e P2), em que a mãe tinha 23 anos e o pai 24, mas cuja primeira filha nascera quando ela tinha 19 anos e ele, 20 anos de idade. Nota-se que condições para o exercício da parentalidade são distintas, pois o que mais fica evidente é que, no caso de M2 e P2, já havia uma relação conjugal e a constituição da família ao nascimento da primeira filha. Tanto M2 quanto P2 estavam bem colocados em sua função parental, pois P2 ficava com a filha para que a M2 concluísse o Ensino Médio. Esse fato não era observado na relação de M1 e P1, pois este mantinha interesses e comportamentos semelhantes aos que tinha antes de ter o seu filho, reunindo os amigos para jogar videogame e fazendo barulho sem perceber as demandas do cuidado com o bebê.

Além disso, P1 era violento e pouco receptivo às solicitações de M1, que acabava por assumir sozinha o cuidado com o bebê, abandonando os estudos. Isso tudo ocorria apesar de ambos os casais estarem felizes com a chegada do bebê e de terem uma renda familiar similar. Nos casos, era possível perceber que, no início, a forma de vivenciar a gravidez na adolescência de M1 com B1 e M2 com a primeira filha foi positiva, a exemplo de mães do estudo de Santos e Schor (2003), mas que a condição familiar de M1 (falta de apoio do companheiro) induziu a uma crescente dificuldade no cuidado com o bebê, que também houve o abandono do estudo por M1, o que foi observado por Ogido e Schor (2012) em outra pesquisa.

Quando se analisa o estudo epidemiológico de Crestani, Mattana, Moraes e Souza (2013) que encontrou, na mesma cidade onde residem M1 e M2, uma relação importante entre renda familiar per capita inferior a $\mathrm{R} \$ 200,00$ representando um risco ao desenvolvimento seis vezes maior a outras condições de renda familiar, percebe-se que o resultado apresenta sentido para M1, mas não para M2, embora ambas estejam na faixa de vulnerabilidade. Por outro lado, se consideradas as condições familiares, sobretudo o apoio à mãe realizado pelo cônjuge, outro aspecto ressaltado no estudo de Crestani et al. (2013), pode-se encontrar uma compreensão maior das diferenças que se instalam no cuidado ao bebê nos dois casos. Enquanto M1 não possui o apoio necessário, M2 o tem. Isso permite uma visão mais compreensiva da situação em cada caso, pois os aspectos sociais não são vistos como algo externo à saúde. Eles criam as condições cotidianas em que as interações se dão, nas quais as experiências vividas no 
tempo constroem novas possibilidades (Latour, 2012; Santos, 1988). O cuidado de M1 a B1 se modifica, possivelmente pelo processo de desamparo familiar e social que lhe traz tristeza, que se reflete no dia a dia com o bebê e é sentida por ele. Apesar de a mãe estar provendo um cuidado físico suficiente ao bebê, o cuidado, de um ponto de vista mais amplo do desenvolvimento, não é suficientemente bom (Winnicott, 2006). A mãe e o bebê deixam de investir na geração de uma linguagem particular comum (Laznik, 2013), o que se reflete na ausência de vocalizações de B1 nas cenas filmadas na terceira etapa. Esse fato contrasta com a cena de M2 e B2 na terceira etapa, em que a linguagem particular não só é construída como se desenvolve e se reflete na presença de recursos crescentes de vocalização de B2.

A observação do comportamento materno no tempo, e no caso de M1, de sua mudança, permite entender como as condições sociais e psíquicas de ambas interferem de modo distinto e singular no desenvolvimento dos bebês e colocam em questão a separação entre biológico e social na abordagem da saúde, como ressaltado por Garbois et al. (2014). Considerando que B1 está em processo de amadurecimento pessoal (Winnicott, 2006) e que esse ele influencia e é influenciado por sua constituição linguística (Ramos \& Flores, 2013; Silva, 2009), percebe-se que o que o bebê traz como carga genética, aparentemente normal aos olhos do pesquisador, poderá ter uma expressão genética distinta (epigenética), partindo do que o meio lhe oferece (Laznik, 2013). B1 não possui nenhum impedimento orgânico para vocalizar, mas a tristeza de sua mãe produz uma evitação na interação que o faz vocalizar e olhar menos, o que já se evidencia como risco ao desenvolvimento, conforme vários estudos atuais (Beltrami et al., 2013; Laznik, 2013; Pretto-Carlesso et al., 2014). Não se sabe até o momento da coleta final se o desfecho será um distúrbio de linguagem ou alguma outra dificuldade no desenvolvimento de B1. Sabe-se, no entanto, que há uma situação de risco ao desenvolvimento do bebê aumentada por uma condição social singular, em que vários fatores se combinam de modo complexo, pois, embora similares aos encontrados no caso 2, produzem efeitos distintos.

Ambas as mães estão no grupo de vulnerabilidade social para problemas na maternidade conforme Santos Neto, Alves, Zorzal e Lima (2008) e também corroboram os resultados encontrados por Novellino (2011) na descrição do perfil de mães adolescentes brasileiras, mas os resultados são distintos, confirmando, mais uma vez, a necessidade de um olhar compreensivo sobre os efeitos do social no desenvolvimento infantil. Considerando a primeira experiência de $\mathrm{M} 2$ e a disposição inicial de M1, a idade não parece ser o fator determinante para o exercício da maternidade. Esse fato já havia sido relatado no estudo de Crestani et al. (2013) em que as mães abaixo de 20 anos tiveram filhos com menor frequência de risco ao desenvolvimento do que as mães entre 20 e 35 anos. Esse fato parece ressaltar que a maternidade na modernidade necessita de uma abordagem mais compreensiva, pois, justamente no melhor período biológico para a reprodução, as mulheres parecem enfrentar desafios em termos de saúde mental e do cuidado com seus filhos. Esse fato já foi ressaltado por Pegoraro e Caldana (2008) quando abordaram o fato de que muitos sintomas físicos e psíquicos das mulheres se relacionam a situações de vulnerabilidade social, entendida de um modo amplo e não apenas restrita ao fator renda e idade.

As observações realizadas nesta pesquisa parecem indicar que a maternidade na adolescência, quando em situação de vulnerabilidade social, pode representar um risco ao desenvolvimento do bebê, não apenas pela baixa renda em si, mas quando ela se associa ao baixo capital social (Ferreira \& Latorre, 2012), o que parece evidente no caso 1. Cabe ressaltar, no entanto, que se está diante de uma situação em que não se apresenta uma patologia ou doença e que poderia ser resolvida no âmbito da atenção primária se houvesse um acolhimento e acompanhamento materno diferenciado. Para tanto, há a necessidade de se superar a ideia de saúde mental vinculada ao transtorno e doença como propõem Moliner e Lopes (2013) e fugir do modelo hospitalocêntrico em saúde mental (Pereira \& Costa-Rosa, 2012). É preciso encontrar estratégias de intervenção social que apoiem mães que se encontrem nesse grupo vulnerável, a partir de uma leitura singular de cada caso.

\section{Considerações Finais}

Para finalizar, cabe destacar que os casos analisados sugerem que os Determinantes Sociais da Saúde podem ser relevantes para o desenvolvimento infantil. Demonstrou-se que as condições em que as famílias acompanhadas vivem, incluindo fatores de trabalho, sociais, econômicos, culturais, psicológicos e comportamentais do casal parental incidem de maneira a beneficiar ou a desfavorecer o potencial do bebê para o amadurecimento e desenvolvimento da linguagem.

Quanto às contribuições do estudo de casos longitudinais para investigações sobre o desenvolvimento do 
bebê, nota-se que os Determinantes Sociais da Saúde são dinâmicos e alteram-se com o passar do tempo. Quando vistos de modo isolado, podem não ser reveladores quanto à sua influência no desenvolvimento infantil. A combinação entre eles e o surgimento de outras condições familiares, como conflitos conjugais, mudanças na rotina familiar, adoecimentos, mortes e mudanças de domicílio podem ser gatilho de condições favoráveis ou desfavoráveis para o desenvolvimento da criança, conforme foi observado nos casos analisados.

Além disso, a análise do desenvolvimento infantil a partir das características individuais de cada um dos membros do casal parental, das condições sociais e das características do próprio bebê, que são mutáveis no decorrer do desenvolvimento dos primeiros meses de vida, permite a compreensão mais adequada se há ou não risco ao desenvolvimento, e também viabiliza ações preventivas. Assim, os estudos de caso longitudinais são uma abordagem metodológica de pesquisa valorosa, que permitem a visão processual do desenvolvimento das crianças e das interações familiares.

Algumas limitações deste estudo foram levantadas, como a influência do uso de equipamentos de filmagem e a ausência dos pais dos bebês durante as coletas. Esta pesquisa foi realizada por meios de filmagens das relações familiares em seu ambiente doméstico, antecedidas de um rapport em que as famílias foram orientadas a interagir de modo habitual. A vantagem dessa proposta está em mostrar as famílias em seus meios naturais e em condições de vida cotidiana. Ainda assim, não é possível desconsiderar, para fins de análise, a inevitável artificialidade imposta pela câmera e pela presença da pesquisadora e esse é um limite que dificilmente é superado em pesquisas com pessoas. Nota-se também que os pais dos bebês acompanhados não estavam presentes durante as filmagens e esse é um aspecto que traz prejuízos para a discussão proposta neste trabalho. Ambas as famílias residiam em locais de difícil acesso, portanto, as coletas foram realizadas durante o dia, período no qual os pais estavam envolvidos em atividades laborais ou de lazer com amigos. Desse modo, as informações sobre os pais dos bebês advêm de relatos das mães. Sugere-se que pesquisas futuras que proponham abordagem metodológica semelhante, realizem a coleta de dados em diferentes momentos do dia e da noite, com especial atenção à presença de todos os integrantes da família.

Por último, a observação quanto à relação mãe-bebê de mutualidade, ou seja, a averiguação sobre a reciprocidade e a sintonia entre a mãe e o bebê pode ser reveladora no que se refere à saúde do bebê, em sua integralidade, quando somada a uma avaliação física. As condições complexas e singulares no dia a dia do cuidado familiar a um bebê são influenciadas também por condições próprias dele, que dizem respeito à natureza humana (a um cuidado exigente) e às demandas habituais por alimento, colo, segurança, silêncio e contato humano. Nesse sentido, as medidas de peso, altura e crescimento do bebê não são suficientes para determinar a sua saúde, pois alguns prejuízos no desenvolvimento não se refletem necessariamente em déficits nessas medidas. Essa avaliação abrangente amplia o escopo da atenção materno-infantil e mostra que o acompanhamento minucioso das famílias e de seus bebês não deve restringir-se, apenas, aos casos em situação de risco orgânico, como usualmente é observado no sistema de saúde.

\section{Referências}

Amorim, R. C. A., Laurentino, G. E. C., Barros, K. M. F. T., Ferreira, A. L. P. R., Moura Filho, A. G., \& Raposo, M. C. F. (2009). Programa de saúde da família: Proposta para identificação de fatores de risco para o desenvolvimento neuropsicomotor. Brazilian Journal of Physical Therapy, 13(6), 506-513. doi: 10.1590/S1413-35552009005000065

Andrade, S. A., Santos, D. N., Bastos, A. C., Pedromônico, M. R. M., Almeida-Filho, N. de, \& Barreto, M. L. (2005). Ambiente familiar e desenvolvimento cognitivo infantil: Uma abordagem epidemiológica. Revista de Saúde Pública, 39(4), 606-611. doi: 10.1590/S0034-89102005000400014

Barre, N., Morgan, A., Doyle, L. W., \& Anderson, P. J. (2011). Language abilities in children who were very preterm and/or very low birth weight: a metaanalysis. The Journal of Pediatrics, 158(5), 766-774. doi: $0.1016 /$ j.jpeds.2010.10.032

Beltrami, L., Moraes, A. B. de, \& Souza, A. P. R. de. (2013). Ansiedade materna puerperal e risco para o desenvolvimento infantil. Distúrbios da Comunicação. ISSN 2176-2724, 25(2).

CDSS-Comissão para os Determinantes Sociais da Saúde. (2010). das Redução Desigualdades no Período de Uma Geração: Igualdade na Saúde atraves da Acção Sobre os SEUS Determinantes Sociais - OMS. Recuperado de http://apps.who.int/bookorders $/$ anglais $/$ detart1.jsp? $\operatorname{codlan}=8 \& \operatorname{cod} c o l=1$ $5 \& \operatorname{codcch}=741$ 
Crestani, A. H., Mattana, F., Moraes, A. B. de, \& Souza, A. P. R. de. (2013). Fatores socioeconômicos, obstétricos, demográficos e psicossociais como risco ao desenvolvimento infantil. Revista CEFAC, 15(4), 847-856. doi: 10.1590/S1516-18462013000400013

Deus, V. F. de. (2010). A especificidade da transcrição com base enunciativa na clínica fonoaudiológica. Universidade Federal do Rio Grande do Sul. Recuperado de http://biblioteca.versila.com/2450021/a-especificidade-da-transcricao-com-base-enunciativa-na-clinica-fonoaudiologica

Fernandes, L. V., Goulart, A. L., Santos, A. M. N. dos, Barros, M. C. de M., Guerra, C. C., \& Kopelman, B. I. (2012). Avaliação do neurodesenvolvimento de prematuros. Jornal de Pediatria, 88(6), 471-478. doi: 10.1590/S0021-75572012000600005

Ferreira, M. A. F., \& Latorre, M. do R. D. de O. (2012). Desigualdade social e os estudos epidemiológicos: Uma reflexão. Ciência \& Saúde Coletiva, 17(9), 25232531. doi: 10.1590/S1413-81232012000900032

Fraga, D. A. de, Linhares, M. B. M., Carvalho, A. E. V., \& Martinez, F. E. (2008). Desenvolvimento de bebês prematuros relacionado a variáveis neonatais e maternas. Psicologia Em Estudo, 13(2), 335-344. doi: 10.1590/S1413-73722008000200016

Fundação Oswaldo Cruz (FIOCRUZ). (2015). Determinantes sociais - SUS: O que são? Leia mais no Pense SUS. Fiocruz. Recuperado de http://pensesus.fiocruz.br/determinantes-sociais

Kruel, C. S. (2015). O amadurecimento do bebê e a linguagem: Uma leitura a partir de Winnicott e Benveniste. Universidade Federal de Santa Maria.

Kruel, C. S., Rechia, I. C., Oliveira, L. D., \& Souza, A. P. R. de. (2016). Categorias enunciativas na descrição do funcionamento de linguagem de mães e bebês de um a quatro meses. CoDAS, 28(3), 244-251. doi: $10.1590 / 2317-1782 / 20162015190$

Latour, B. (2012). Reagregando o social: Uma introdução à teoria do ator-rede. Salvador: Edufba, Bauru: Edusc.

Laznik, M. C. (2013). Linguagem e comunicação do bebê de zero aos três meses. Em M. C. Laznik (Ed.), A hora e a vez do bebê. São Paulo: Instituto Langage.

Magalhães, K. A., Cotta, R. M. M., Gomes, K. de O., Franceschinni, S. do C. C., Batista, R. S., \& Soares, J. B. (2011). Entre o conformismo e o sonho:
Percepções de mulheres em situação de vulnerabilidade social à luz das concepções de Amartya Sen. Physis: Revista de Saúde Coletiva, 21(4), 1493-1514. doi: 10.1590/S0103-73312011000400017

Moliner, J. de, \& Lopes, S. M. B. (2013). Saúde mental na atenção básica: Possibilidades para uma prática voltada para a ampliação e integralidade da saúde mental. Saúde e Sociedade, 22(4), 1072-1083. doi: 10.1590/SAUSOC.V22I4.76501

Novellino, M. S. F. (2011). Um estudo sobre as mães adolescentes brasileiras. Physis: Revista de Saúde Coletiva, 21(1), 299-318. doi: 10.1590/ S0103-73312011000100018

Ogido, R., \& Schor, N. (2012). A jovem mãe e o mercado de trabalho. Saúde Soc, 21(4), 1044-1055. doi: 10.1590/S0104-12902012000400021

Pariz, J., Mengarda, C. F., \& Frizzo, G. B. (2012). A atenção e o cuidado à gravidez na adolescência nos âmbitos familiar, político e na sociedade: Uma revisão da literatura. Saúde Soc, 21(3), 623-636.

Pedrosa, A. A. (2012). Gravidez e transição para a maternidade na adolescência determinantes individuais e psicossociais da ocorrência de gravidez e da adaptação. Estudo com adolescentes da Região Autónoma dos Açores. Universidade de Coimbra, Potrugal.

Pegoraro, R. F., \& Caldana, R. H. L. (2008). Mulheres, loucura e cuidado: A condição da mulher na provisão e demanda por cuidados em saúde mental. Saúde Soc., 17(2), 82-94. doi: 10.1590/ S0104-12902008000200009

Pereira, E. C., \& Costa-Rosa, A. (2012). Problematizando a reforma psiquiátrica na atualidade: A saúde mental como campo de práxis. Saúde Soc., 21(4), 10351043. doi: 10.1590/S0104-12902012000400020

Pretto-Carlesso, J. P., Souza, A. P. R., \& Moraes, A. B. (2014). Análise da relação entre depressão materna e índices clínicos de risco para o desenvolvimento infantil. Rev. CEFAC, 16(2), 500-509. Recuperado de http://www.scielo.br/pdf/rcefac/ v16n2/1982-0216-rcefac-16-2-0500.pdf

Ramos, A. P., \& Flores, V. N. (2013). A passagem de locutor a sujeito como efeito do processo e apropriação na clínica da infância: Estudo de um caso. Em B. M-C. \& M. R. G. (Eds.), O bebê e as palavras: Uma visão transdisciplinar sobre o bebê (pp. 185-200). São Paulo: Instituto Langage.

Psico-USF, Bragança Paulista, v. 23, n. 1, p. 83-94, jan./mar. 2018 
Rodrigues, O. M. P. R. (2012). Escalas de desenvolvimento infantil e o uso com bebês. Educar em Revista, 43, 81-100. doi: 10.1590/S0104-40602012000100007

Sabroza, A. R., Leal, M. C., Gama, S. G. N., \& Costa, J. V. (2004). Perfil sociodemográfico e psicossocial de puérperas adolescentes do município do Rio de Janeiro, Brasil - 1999-2001. Cad. Saúd. Públic, 20(1), 112-120. doi: 10.1590/S0102-311X2004000700012

Santos, B. (1988). Um discurso sobre as ciências na transição para uma ciência pós-moderna. Estudos Avançados, 2(2), 46-71.

Santos, S. R., \& Schor, N. (2003). Vivências da maternidade na adolescência precoce. Rev Saúde Públic, 37(1), 15-23.

Santos Neto, E. T., Alves, K. C. G., Zorzal, M., \& Lima, R. C. D. (2008). Políticas de saúde materna no Brasil: Os nexos com indicadores de saúde materno-infantil. Saúde Soc, 17(2), 107-119. doi: 10.1590/ S0104-12902008000200011

Silva, C. L. C. (2009). A criança na linguagem: Enunciação e aquisição. Campinas: Pontes Editores.

Taques, D. C. S. R., \& Rodrigues, O. M. P. R. (2006). Avaliação do repertório comportamental de bebês nos quatro primeiros meses de vida: Uma proposta de análise. Rev. Bras. Crescimento Desenvolv. Hum, 16(2), 88-87.

Vieira, M. L. F., Bicalho, G. G., Silva, J. L. C. P., \& Barros Filho, A. (2007). Crescimento e desenvolvimento de filhos de mães adolescentes no primeiro ano de vida. Rev. Paul. Ped., 25(4), 343-348. doi: 10.1590/ S0103-05822007000400008

Voss, W., Jungmann, T. Wachtendorf, M., \& Neubauer, A. P. (2012). Long-term cognitive outcomes of extremely low-birth-weight infants: The influence of the maternal educational background. Acta Paediatrica, 101, 569-573. doi: 0.1111/j.1651-2227.2012.02601.x.

Wanderley, D., Weise, E. B. ., \& Brant, J. A. (2008). O que há de avaliável no desenvolvimento infantil? Exame e discussão das escalas de avaliação do desenvolvimento infantil mais usadas no Brasil. Em R. Lerner \& M. C. Kupfer (Eds.), Psicanálise com crianças: Clínica e pesquisa (pp. 109-114). São Paulo: FAPESP.

Winnicott, D. W. (1969). A experiência mãe-bebê de mutualidade. Em Explorações Psicanalíticas. Porto Alegre: Artes Médicas.

Winnicott, D. W. (2006). Os bebês e suas mães. São Paulo: Martins Fontes.

Winnicott, D. W. (2012). A criança e seu mundo (6th ed.). Rio de Janeiro: LTC.

Yin, R. K. (2001). Estudo de caso: Planejamento e métodos $\left(2^{\mathrm{a}}\right)$. Porto Alegre: Bookman.

Recebido em: 18-02-2016

Reformulado em: 14-09-2016; 26-10-2016

Aprovado em: 07-11-2016 
Sobre as autoras:

Cristina Saling Kruel é psicóloga, mestre em Psicologia (UFRGS) e doutora em Distúrbios da Comunicação Humana pela Universidade Federal de Santa Maria (UFSM). Atualmente, é professora adjunta na Universidade Franciscana (UFN) na graduação e no Mestrado Profissional em Saúde Materno Infantil. Também coordena o Núcleo de Estudos e Pesquisas sobre Parentalidade e Primeira Infância (NEPRI), que tem como enfoque aspectos emocionais do período gravídico-puerperal e humanização do nascimento, direitos sexuais e reprodutivos das mulheres, desenvolvimento emocional bebê e primeira infância.

E-mail: cristinaskruel@gmail.com

Ana Paula Ramos de Souza é founoaudióloga, mestre em Linguística e Letras (PUCRS), doutora em Linguística (PUCRS) e pós-doutora em Letras (UFRGS). Atualmente é professora do quadro efetivo do departamento de Fonoaudiologia da Universidade Federal de Santa Maria ministrando disciplinas da área de linguagem e do campo comunitário nos cursos de graduação em Fonoaudiologia e no Programa de Pós-Graduação em Distúrbios da Comunicação Humana.

E-mail:ana.souza@ufsm.br

Contato com as autoras:

Cristina Saling Kruel

Centro Universitário Franciscano

Rua Silva Jardim, 1175. Conjunto III

Santa Maria-RS, Brasil

CEP: $97010-491$ 